\title{
0-D-Modelling of Carbonaceous Aerosols over Greater Paris Focusing on the Organic Particle Formation
}

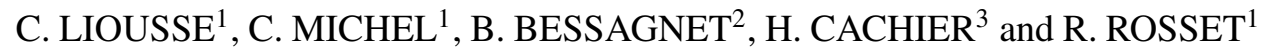 \\ ${ }^{1}$ Laboratoire d'Aérologie, CNRS-UPS, UMR 5560, 14 ave E. Belin, 31400 Toulouse, France, \\ e-mail:lioc@aero.obs-mip.fr \\ ${ }^{2}$ INERIS, Direction des Risques Chroniques, Modélisation et Analyse Economique pour la gestion \\ des Risques (MECO), Parc Technologique ALATA-BP $n^{\circ}$ 2, 60550 Verneuil en Halatte, France \\ ${ }^{3}$ Laboratoire des Sciences du Climat et de l'Environnement, CNRS-CEA, Ave de la Terrasse, \\ 91 198-Gif sur Yvette Cedex, France
}

\begin{abstract}
To improve our understanding of aerosol formation and ageing in urban atmospheres, we have tested the ORISAM 0-D aerosol module (ORganic and Inorganic Spectral Aerosol Model). This module accounts for both types of primary carbonaceous particles (black carbon BC and primary organic carbon $\mathrm{OC}_{\mathrm{p}}$ ) and also simulates the formation of secondary inorganic and organic particles (sulfates, nitrates, ammonium, water and secondary organic carbon particles $\mathrm{OC}_{\mathrm{sec}}$ by attachment of gas precursors to pre-existing carbonaceous particles. Simulations were performed for surface aerosols over Greater Paris area during the ESQUIF summer 1998 and winter 2000 experiments. Results show that $\mathrm{OC}_{\mathrm{sec}}$ formation is highly dependent on temperature and insolation with more intense secondary formation in summer than in winter. Moreover in Summer, when atmospheric conditions shift from warm and humid to hot and dry, the model indicates a decreasing formation of secondary organic aerosols $\mathrm{OC}_{\mathrm{sec}}$ as shown by an increase of the $\mathrm{OC}_{\mathrm{p}} /\left(\mathrm{OC}_{\mathrm{p}}+\mathrm{OC}_{\mathrm{sec}}\right)$ ratio from 42 to $56 \%$. These results satisfactorily compare with the few experimental available data for $\mathrm{BC} /\left(\mathrm{OC}_{\mathrm{p}}+\mathrm{OC}_{\mathrm{sec}}\right)$ ratios increasing from 24 to $37 \%$ against modelled values in the range $21-32 \%$. ORISAM module sensitivity to initial size distributions, background concentrations and emissions of gases and primary carbonaceous particles was documented too. One main result is that the formation of secondary organic particles with ORISAM is very sensitive to the concentrations of gaseous precursors. At the present stage of ORISAM development, $\mathrm{OC}_{\mathrm{sec}}$ build up appears to be however less sensitive to particulate background concentrations.
\end{abstract}

Key words: carbonaceous aerosol, secondary organic aerosol formation, urban plumes, modelling

\section{Introduction}

Aerosol particles are often quoted for their overall cooling effect of about the same order of magnitude as the positive forcing by greenhouse gases (Charlson et al., 1992; Haywood and Shine, 1995; Penner et al., 1996; Jacobson, 2002; Chung and Seinfeld, 2002). However, these estimates are still subject to debate even in sign. The primary and most obvious reason is that the relative amount of the absorbing 
fraction (mostly black carbon - BC) among scattering particles (sulphate, nitrate and organic particles) is poorly known. Also, more documentation is required, on the particle size distribution of each aerosol component, their mixing state (internal versus external) and subsequent optical properties. Moreover, due to the strong absorbing component of the urban aerosol mixture, top and bottom of the atmosphere radiative forcing values have been found quite different, involving important columnar heating rates (Léon et al., 2003; Mallet, 2003).

Urban particles are expected to exert a significant direct forcing and to have a significant impact on the oxidising capacity of the atmosphere. They may also play a deletirious role on health (Atkinson et al., 2001; Brauer et al., 2003). Recently only, for urban atmospheres, the importance of carbonaceous particles and particularly of organic particles have been evidenced (Putaud et al., 2003; Cachier et al., 2005). This is partly due to important uncertainties founding the organic particle concentrations, uncertainties primarily related to specific artefacts encountered in both organic aerosol sampling and analysis procedures. Intercomparison of measurements (Schmidt et al., 2001) and methods (http://ocs.fortlewis.edu/Aerosols/OCEC/agenda.htm) have shown that the determination of black carbon and organic carbon contents is operationally defined. Size distributions and the optical and hydrophilic properties of organic particles are also uncertain due to lack of data. Finally, emission inventories proposed in the literature for organic particles can be largely conflicting. A main reason relies in the primary or secondary origin of organic particles. Recent experiments have shown for example that the formation of secondary organic aerosol takes place readily close to sources (Cachier et al., 2005). Due to this complexity, large discrepancies appear in the proposed global budgets if only the primary origin is considered (Cooke et al., 1999), or the secondary origin (Kanakidou and Tsigaridis, 2000) or both (Liousse et al., 1996).

Aiming to better understand the formation of organic particles and to contribute to the construction of realistic budgets, a 0-D aerosol module ORISAM (ORganic and Inorganic Spectral Aerosol Model) was developed at Laboratoire d'Aérologie (France). This aerosol module has first been used to simulate urban aerosol formation and transformation. Our urban case study applied to the Greater Paris area for summer 1998 and winter 2000 and relied on the ESQUIF experiment (Etude et Simulation de la QUalité de l'air en Ile de France (see http://www.aero.jussieu.fr/themes/CA/Projet\%20ESQUIF.html). The few existing measurements for carbonaceous aerosols were used to validate parameterizations and to run sensitivity tests.

\section{The Modelling Procedure}

\subsection{THE 0-D AEROSOL MODEL}

The ORISAM 0-D model is illustrated by the flow diagram in Figure 1. The module allows aerosol mixing and evolution by considering the formation of secondary 


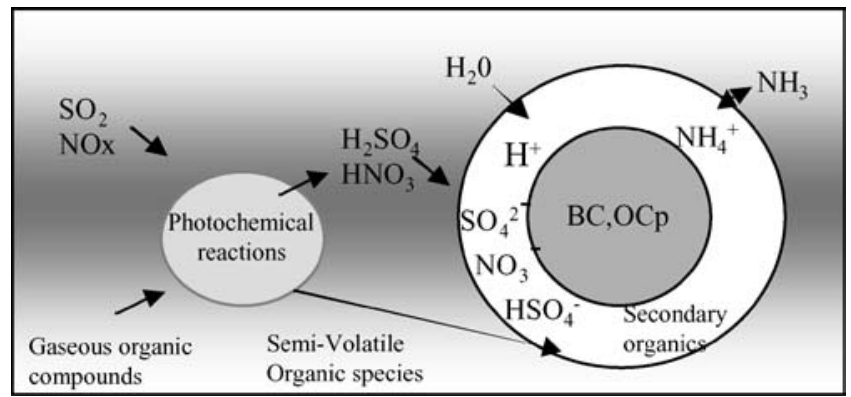

Figure 1. General schematic representation of ORISAM.

aerosols through coating of pre-existing insoluble aerosols. ORISAM relies on previous works of Bessagnet (2000) and Bessagnet and Rosset (2001). In our work, insoluble aerosols have been partitioned into black carbon (BC) and primary organic carbon $(\mathrm{OC})$ and the secondary organic $\left(\mathrm{OC}_{\mathrm{sec}}\right)$ separated according to their origins (anthropogenic/biogenic origins). The secondary inorganic aerosols are sulphates, nitrates, ammonium and water. A sectional representation for aerosol size distribution is adopted with a variable number of sections (Fassi-Fihri et al., 1997).

Coagulation (particle agglomeration), condensation, sedimentation and absorption of semi-volatile species are the different processes taken into account in the microphysical module. The RACM (Regional Atmospheric Chemistry Mechanism) scheme is used to describe the chemistry kinetics in the gas phase (Stockwell et al., 1997). The chemical thermodynamic module ISORROPIA (Nenes et al., 1998) is used to calculate for the inorganic components thermodynamic equilibrium between the particle and gas phases, most of them being highly dependent on atmospheric temperature and humidity. Secondary organic aerosols (SOA) are supposed to originate only from the absorption of volatile organic hydrocarbons onto the surface of primary particles. As it is not possible to account for all the complex, numerous and variable oxidation mechanisms taking place in the gas phase, some of them being even still unknown and in order to maintain reasonable computer time, SOA formation is parametrized. Following Wang et al. (1992), an alternative way is to simulate this formation by a two-step process: firstly, the total mass of condensable organic gases is obtained using an empirical method relying on experimental constant yields $(Y)$, and secondly, temperature-dependent partitioning coefficients $\left(K_{\mathrm{p}}\right)($ Odum et al., 1996) are used to derive SOA mass.

\subsection{AEROSOL MODEL INITIALIZATION}

\subsubsection{Period of Simulation}

Two specific days were chosen during the summer 1998 dataset. Simulations were also conducted for 3 days of winter 2000 for sensitivity tests, though no experimental 
data exist for this latter period. All selected days were chosen without rain and for their contrasted conditions (high relative humidity $(\mathrm{RH})$ and low temperature, high temperature and low $\mathrm{RH}$, low temperature and low $\mathrm{RH}$ ).

\subsubsection{Meteorological Data}

Temperature, relative humidity, radiance, and boundary-layer thickness are necessary.

As shown in Figure 2 which display profiles of relative humidity and temperature, measured in Paris every hour and interpolated every minute for model input. August 7th, 1998, was quite hot (average temperature $23^{\circ} \mathrm{C}$ ) and dry (average relative humidity $47 \%)$. On the contrary, July 28 th, 1998 , was colder $\left(17^{\circ} \mathrm{C}\right)$, with reduced temperature diurnal amplitude, and much more humid (80\%).

For winter 2000 , January 22 nd was cold $\left(5^{\circ} \mathrm{C}\right.$ in the average) and humid (average relative humidity $81 \%)$; January 25 th was still colder $\left(-0.9^{\circ} \mathrm{C}\right.$ mean) and quite dry $(49 \%)$, whereas January 30 th was warmer $\left(11^{\circ} \mathrm{C}\right)$ and also quite humid $(81 \%)$.

The boundary layer thickness ranged from $410 \mathrm{~m}$ to $1886 \mathrm{~m}$ in summer during ESQUIF, whereas 105-787 m for winter urban conditions. In the model, a sinusoidal function is used to reproduce the daily variation of the boundary layer thickness. The daily variation of radiances needed for the simulation, is inferred from the TUV radiation model (Tropospheric Ultraviolet and Visible radiation model), developed by Madronich and Flocke (1998).

\subsubsection{Emissions}

The same emissions are used for the different cases, whatever the season (summer and winter days) in order to focus on the impact of meteorological conditions only. The emissions of the anthropogenic gases (hydrocarbons, $\mathrm{SO}_{2}, \mathrm{NH}_{3}, \mathrm{NO}_{x}$ ), are extracted from the GENEMIS database (GENeration of an EMIssion database, http://www.ier.unistuttgart.de/public/de/organisation/abt/tfu/projekte/genemis/ GENEMIS.html) with a $3 \mathrm{~km}$ spatial resolution. The gaseous species in the GENEMIS database differ from those introduced in the RACM regional model, so aggregation factors were used for adaptation (Stockwell et al., 1997). The biogenic emissions (isoprene, monoterpenes) are obtained from a simulation for the Paris area performed with the Meso-NH-C model (Solmon, 2001). Let us note that, as described later in the paper, these choices are determinant to fix the background gaseous concentrations and then the SOA formation. Emission fluxes are given for 1-h time intervals for anthropogenic gases and 3-h time interval for biogenic gases, and subsequently interpolated to 1-min intervals.

$\mathrm{BC}$ and primary OC emission fluxes are obtained from a new inventory constructed for the year 1997 (Liousse et al., 2004). As no experimental data for carbonaceous aerosol size were available in ESQUIF we assumed the same distribution 

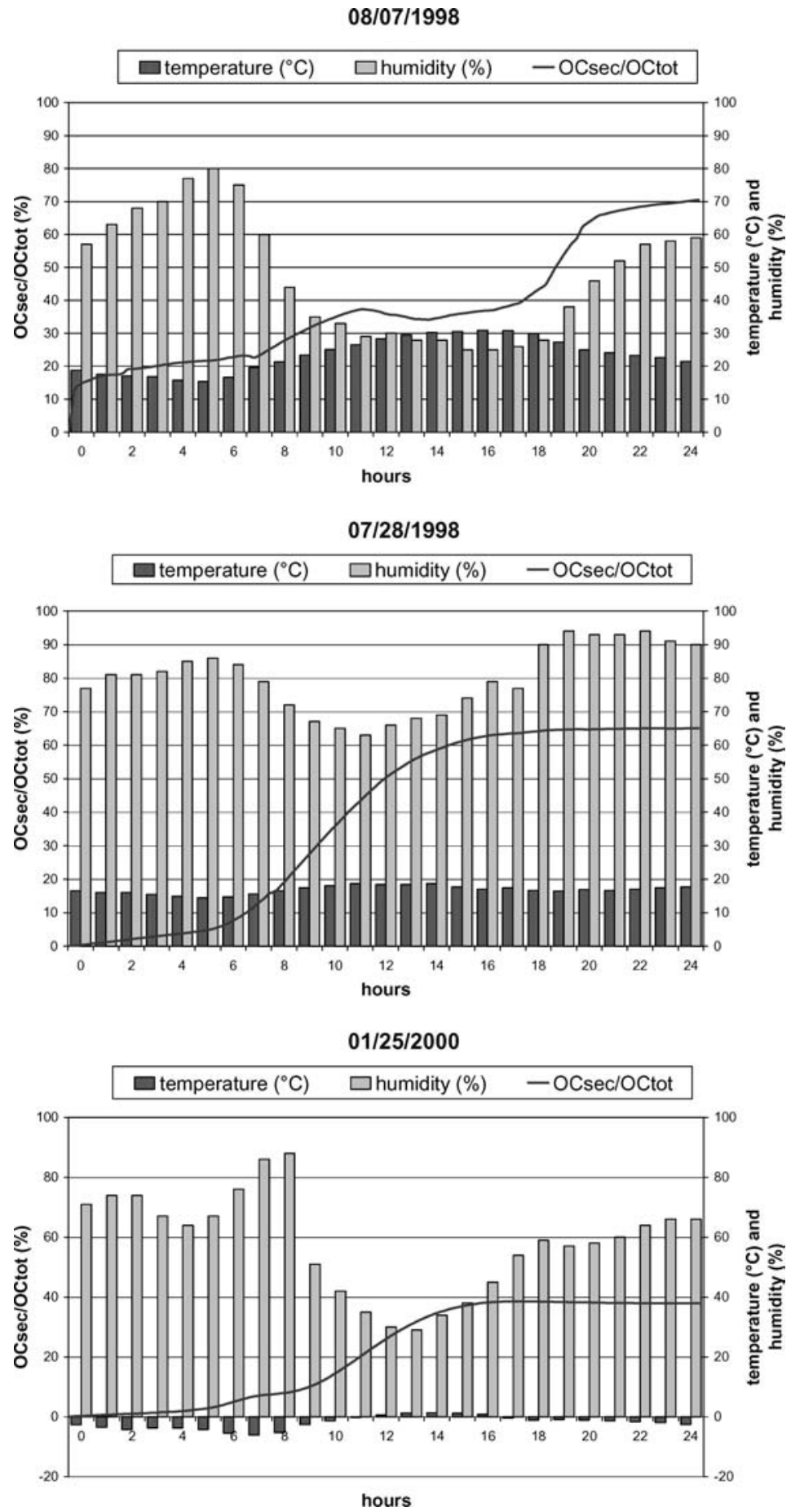

Figure 2. Daily evolutions of temperature, relative humidity and $\mathrm{OC}_{\mathrm{sec}} / \mathrm{OC}_{\mathrm{tot}}$ ratio (\%) for (a) August 7th, 1998, (b) July 28th, 1998 and (c) January 25th, 2000. 
as in Chazette and Liousse (2001). The uncertainty due to particle size is certainly rather high as shown by the preliminary sensitivity tests presented later in this paper. A two-mode log-normal distribution is considered. The first mode, assumed centred at $0.1 \mu \mathrm{m}$ (mass diameter size) contains only 50\% BC mass. The second mode is centred at $0.23 \mu \mathrm{m}$ with $100 \%$ of primary OC mass and $50 \%$ of $\mathrm{BC}$ mass.

\subsubsection{Background Concentrations}

Initial background gas concentrations were obtained at 00:00 local time (LT) after a spin-up period covering the whole day before. Different references for aerosol initialisation were chosen. Preliminary simulations presented in paragraph 3.1, point to high variabilities in $\mathrm{BC}$, primary $\mathrm{OC}$, secondary organic aerosol during the day and maximum concentrations at night (00:00 LT) due to accumulation processes. Indeed, no particle sink is taken into account in this modelling exercise (no particle deposition nor dynamical evolution except evolution of the boundary-layer thickness). Therefore, the mean state obtained by averaging aerosol concentrations the day before is that chosen for initialisation (called init-mean in the following). For example, primary carbonaceous aerosol concentrations for the 08/07/98 are $1.53 \mu \mathrm{g} / \mathrm{m}^{3}$ (50\% BC) for the first mode and $7.87 \mu \mathrm{g} / \mathrm{m}^{3}$ (50\% BC and 100\% OC) for the second mode.

\section{Modelling Results}

\subsection{SIMULATED AEROSOL EVOLUTION}

Figures 3a-c display the evolution of the different aerosol components obtained respectively for 3 days: August 7th and July 28th, 1998 and January 25th, 2000. Results are presented at 0:00, 12:00 and 24:00 LT. The secondary aerosols either inorganic (sulphates, nitrates, ammonium and water) or organic (SOA) display increasing concentrations with the hour of the day, and marked differences from one meteorological situation to another.

- Concentrations of the secondary inorganic aerosols are quite different for winter and summer days, and appear to be mainly driven by the competitive effects of relative humidity, temperature and photochemical conditions. As shown with the results for summer days (Figures 3a and b), formation of the inorganic aerosol components is twice more important on $07 / 28 / 98\left(28 \mu \mathrm{g} / \mathrm{m}^{3}\right)$ as compared to $08 / 07 / 98\left(13 \mu \mathrm{g} / \mathrm{m}^{3}\right)$, when afternoon relative humidity is higher and temperature lower. The water capture may cause enhancement of the absorption of the different semi-volatile species at the aerosol surface, and thus the formation of secondary inorganic species. The role of photochemistry is illustrated through comparison between the two days January 25th and August 7th with about the same mean atmospheric relative humidity (47 and 49\%): a significant difference 


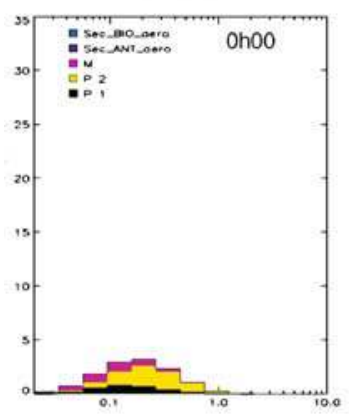

$3 b: 07 / 28 / 98$

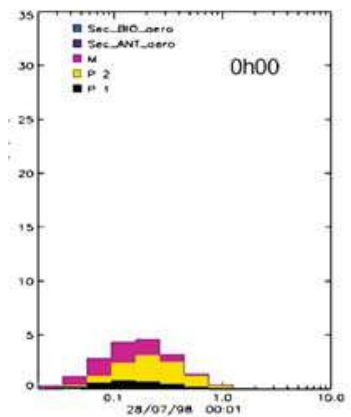

$3 c: 01 / 25 / 00$

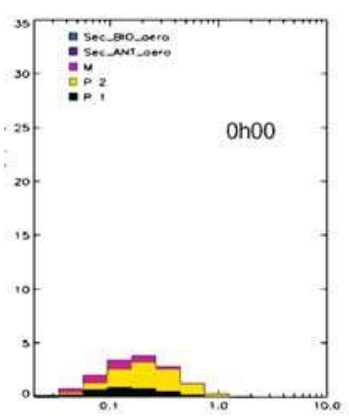

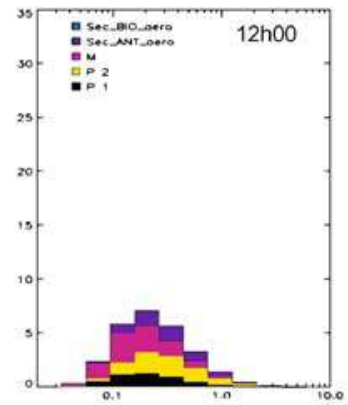

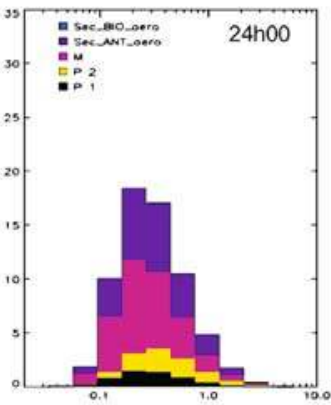

Diameter $(\mu m)$
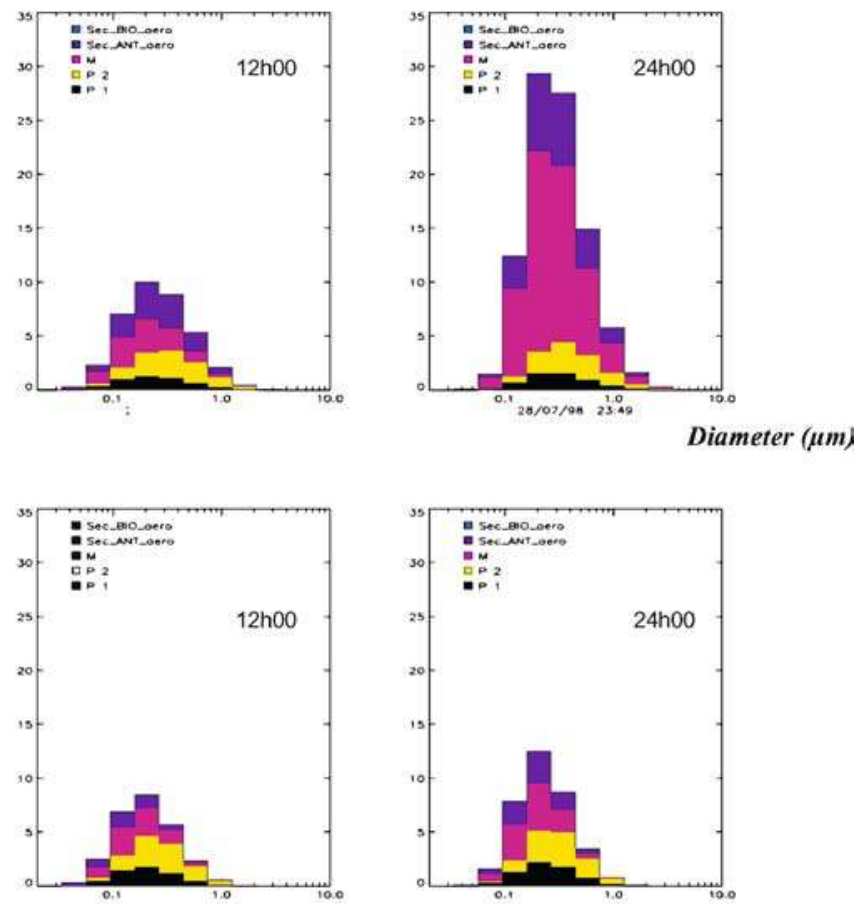

Diameter $(\mu m)$

Figure 3. Evolution of the different aerosol components respectively for (a) August 7th, 1998, (b) July 28th, 1998 and (c) January 25th, 2000 (P1: black carbon, P2: Primary organic carbon, M: water soluble fraction including water, Sec-ant-aero: Anthropogenic Secondary organic aerosol). Sec-bio-aero: Biogenic Secondary organic aerosol.

is there observed for the inorganic aerosol components $\left(7.5\right.$ and $13 \mu \mathrm{g} / \mathrm{m}^{3}$ ) which points to the importance of photochemistry during summer days. This sensitivity to photochemical formation also exists at higher relative humidities (RH about $80 \%$ ), similar differences being observed in winter $\left(11-12.6 \mu \mathrm{g} / \mathrm{m}^{3}\right.$ for 
simulations performed on January 22nd and 30th (results not shown here)) and in summer ( $28 \mu \mathrm{g} / \mathrm{m}^{3}$ for simulations of July $28 \mathrm{th}$ ).

- The formation of secondary organic aerosol generally begins in the early morning due to the conjunction of the morning traffic peak emissions and the onset of photochemistry. When temperature reaches a maximum, secondary aerosol VOC precursors are found predominantly in the gas phase. When the temperature decreases, around 18:00 LT approximately, the transfer of condensable organic species from the gas to the particulate phase may become more important. Such a process, driven by the module parameterizations, is in agreement with the theoretical works of Sheehan and Bowman (2001), who have shown that temperature governs the transfer of organic species from the gas to the particulate phase and conversely. This temperature dependence is illustrated by comparison of the two summer days in which the mean temperature is markedly different: when comparing Figures $2 \mathrm{a}$ and $\mathrm{b}$ to Figure $3 \mathrm{a}$ and $\mathrm{b}$, it may be seen that, with almost similar afternoon photochemistry activity for the two summer days, the relative concentration of secondary organic carbon is weaker on August 7th, 1998 than for the milder day, July 28th 1998 . Such a difference is still enhanced after $24 \mathrm{~h}$ of simulation (11.4 and $7.65 \mu \mathrm{g} / \mathrm{m}^{3}$ on July 28th and August 7th). During the hot and dry day August 7th, SOA formation is reduced when temperature reaches a maximum, as VOCs remain in the gaseous phase. At the end of the afternoon, when temperature decreases, SOA formation again increases, a process which may be favoured by the parallel increase of traffic precursor emission. This SOA formation is still more visible due to the decrease of the boundary layer thickness. For the selected winter days, similar profiles of secondary organic aerosol formation are obtained. However, SOA concentrations are weaker by a factor of two (mean: $4.6 \mu \mathrm{g} / \mathrm{m}^{3}$ in winter whereas $9.5 \mu \mathrm{g} / \mathrm{m}^{3}$ in summer), which may primarily reflect the impact of photochemistry.

\subsection{COMPARISON BETWEEN EXPERIMENTAL AND MODELLED VALUES}

Table I presents $\mathrm{BC} / \mathrm{OC}_{\text {tot }}$ ratio values simulated for the different situations, in winter and summer. It may be recalled that $\mathrm{OC}_{\text {tot }}$ includes both $\mathrm{OC}_{\mathrm{p}}$ and $\mathrm{OC}_{\mathrm{sec}}$. Measured values are shown for the summer experiment. As BC is an inert species, and considering that emissions are the same for the different case studies, any decrease of $\mathrm{BC} / \mathrm{OC}_{\text {tot }}$ ratio may be interpreted as an indicator of secondary $\mathrm{OC}$ production.

A statistically significant difference is observed for mean $\mathrm{BC} / \mathrm{OC}_{\text {tot }}$ ratios obtained by the model in winter (43\%) and in summer (33\%). In winter, lower temperatures and weak radiances create conditions of low photolytic activity of and consequently, weaker SOA formation than in summer. Higher $\mathrm{BC} / \mathrm{OC}_{\text {tot }}$ ratios are thus expected in winter. Interestingly such a seasonal trend in $\mathrm{BC} / \mathrm{OC}_{\text {tot }}$ ratios was experimentally obtained by Castro et al. (1999) for urban areas in Portugal in summer 1993 and winter 1992-1993 in Coimbra (33 and 48\% respectively) and in Oporto (37 and 59\%). 
Table I. Simulated $\mathrm{BC} / \mathrm{OC}_{\mathrm{tot}}$ ratios $(\%)$ for the selected winter and summer days

\begin{tabular}{llllll}
\hline & \multicolumn{4}{c}{ Simulated BC/OC ${ }_{\text {tot }}$ ratio (\%) } & \\
\cline { 2 - 4 } Date & Mean & $0-9 \mathrm{~h}$ & $9-21 \mathrm{~h}$ & $21-24 \mathrm{~h}$ & $\begin{array}{l}\text { Measured BC/OC } \\
\text { ratio (\%) 9-21 h }\end{array}$ \\
\hline $01 / 22 / 00$ & 45 & 49 & 43 & 42 & No data \\
$01 / 25 / 00$ & 45 & 48 & 42 & 42 & No data \\
$01 / 30 / 00$ & 40 & 45 & 37 & 36 & No data \\
$08 / 07 / 98$ & 37 & 42 & $\mathbf{3 7}$ & 21 & $\mathbf{3 2}$ \\
$07 / 28 / 98$ & 29 & 40 & $\mathbf{2 4}$ & 20 & $\mathbf{2 1}$ \\
\hline
\end{tabular}

Note. Summer days with existing experimental data are in bold.

An interesting feature in Table I is also that modelled average values ("mean day values" for the 9-21 h LT time period) compare satisfactorily with experimental values obtained during the summer ESQUIF campaign especially for their trends. Indeed, $\mathrm{BC} \mathrm{OC}_{\text {tot }}$ ratio values for July 28th and August 7 th show the same decrease of a third for either measurements or simulated values. If we recall the important discrepancies appearing for urban carbonaceous aerosol measurements between different analytical protocols (Schmidt et al., 2001), this fair agreement between simulated and experimental values may be coincidental but similar trends of $\mathrm{BC} / \mathrm{OC}_{\text {tot }}$ under different meteorological situations is certainly an indicator of a reasonable parameterisation of the SOA formation in ORISAM for our case study. Furthermore, the experimental values were obtained for Gif sur Yvette aerosols at a suburban location, whereas the modelled values were calculated for central Paris. This difference in location has been shown to introduce a small shift of about $3 \%$ in experimental BC/OC ratios (Ruellan and Cachier, 2001), the pure urban aerosol being enriched in $\mathrm{BC}$. This minor correction still emphasizes the agreement. However, due to the quoted limitations (linked to both experiments and modelling) more data comparisons are needed to actually validate the model SOA formation.

\subsection{SENSITIVITY TESTS UPON INITIALISATION CONDITIONS}

\subsubsection{Impact of Temperature and Relative Humidity on SOA Formation}

Two sets of sensitivity tests have been conducted with the same emissions and initialisations, changing the temperature or the relative humidity only. Figure 4 displays $24 \mathrm{~h}$ averages of values of $\mathrm{OC}_{\mathrm{sec}} / \mathrm{OC}_{\text {tot }}$ ratios obtained for the different simulations. Although comparison is based on $24 \mathrm{~h}$ averages, $\mathrm{OC}_{\mathrm{sec}}$ formation is highly dependent on temperature. However, dependency with the relative humidity is seen to be less important.

Interestingly, a temperature threshold seems to appear around $20^{\circ} \mathrm{C}$, with a sharp decrease of the $\mathrm{OC}_{\mathrm{sec}} / \mathrm{OC}_{\text {tot }}$ ratios around this temperature value. At lower 


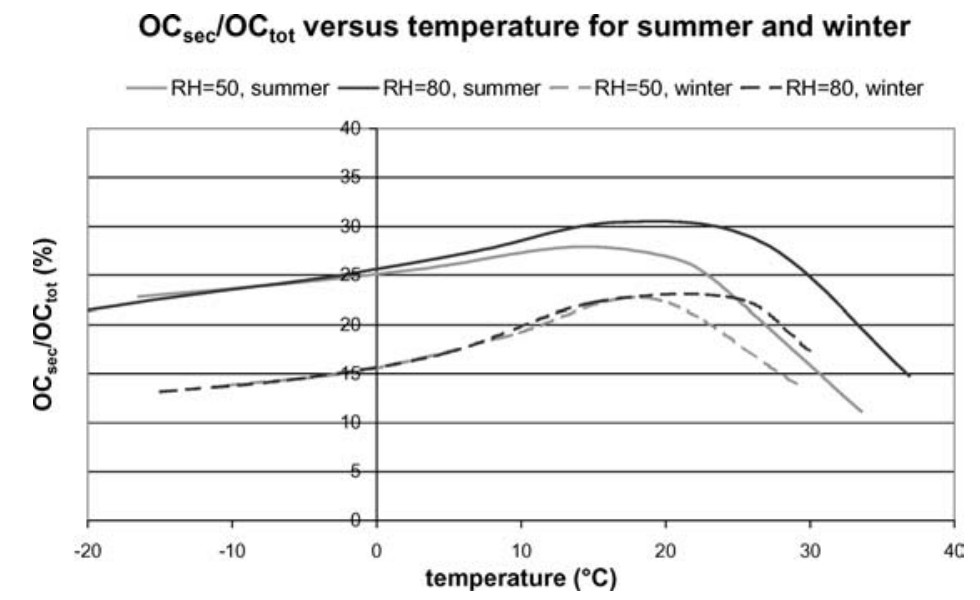

Figure 4. Temperature threshold for $\mathrm{SOA}$ formation as seen by the evolution of the $\mathrm{OC}_{\mathrm{sec}} / \mathrm{OC}_{\mathrm{tot}}$ ratio, for different meteorological conditions: two relative humidity (50 and $80 \%$ ) and two seasonal (winter and summer) insolation conditions.

temperatures, increasing temperature favours the SOA formation with although much less effect. This threshold is apparently the same for both seasons but as expected, photochemical $\mathrm{OC}_{\mathrm{sec}}$ formation is more significant in summer than in winter (up to 50\% more). Such results confirm the hierarchy of processes described in Section 3.1.

\subsubsection{Sensitivity Tests for SOA Formation According to Aerosol and Gaseous PreCursor Initialization}

Different tests were conducted to capture the role of initial concentration levels of aerosol and gaseous precursors. Firstly, the role of the carbonaceous particle size distribution was scrutinized. This parameter is probably the one subject to the larger uncertainties, due to lack of measurements. For the purpose of the tests, particle sizes used for "actual conditions" (Section 2.2: $0.1 \mu \mathrm{m}$ for the first mode and $0.23 \mu \mathrm{m}$ for the second mode) were respectively divided or multiplied by a factor of two. Such a range may account for more recent results (Putaud et al., 2003; Cachier et al., 2005). It was found in our sensitivity tests however, that these changes of particle size have no impact on $\mathrm{OC}_{\mathrm{sec}}$ formation whereas important changes of the particle specific surface are expected with changes in the particulate size distribution.

Secondly, as primary aerosol and gas concentrations have probably a strong impact on SOA formation, different simulations were performed changing concentrations of either the carbonaceous particles or the gases. Figures 5a and $\mathrm{b}$ show the relative increase in secondary organic aerosol due to changes in emissions when aerosol (Figure 5a) and gas amounts (Figure 5b) are successively divided and 


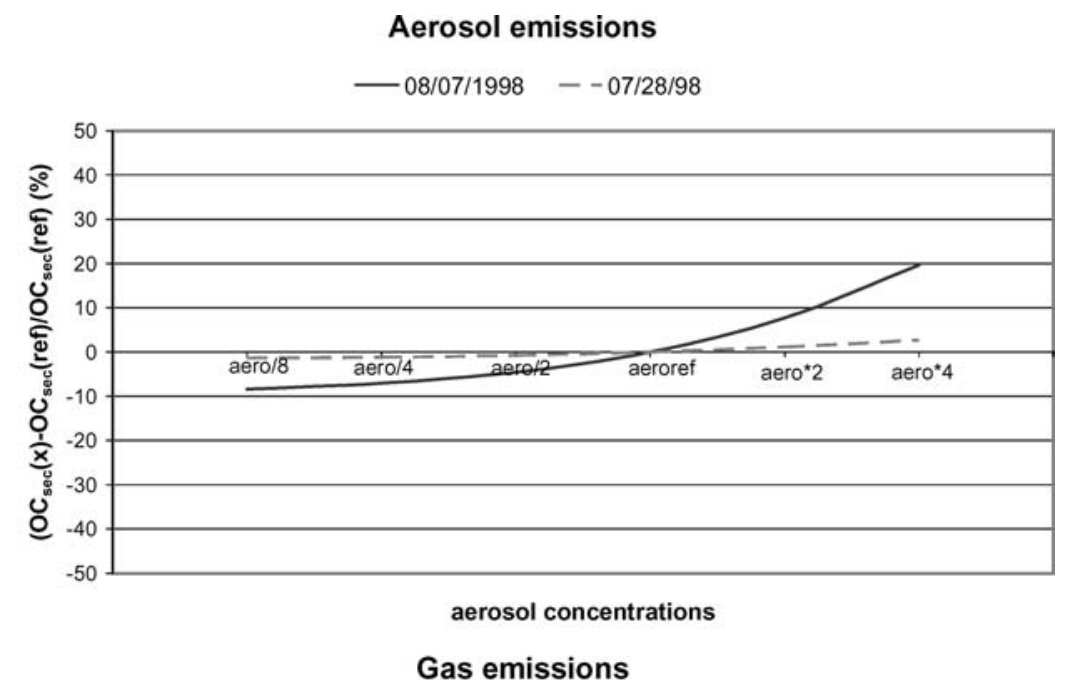

Gas emissions

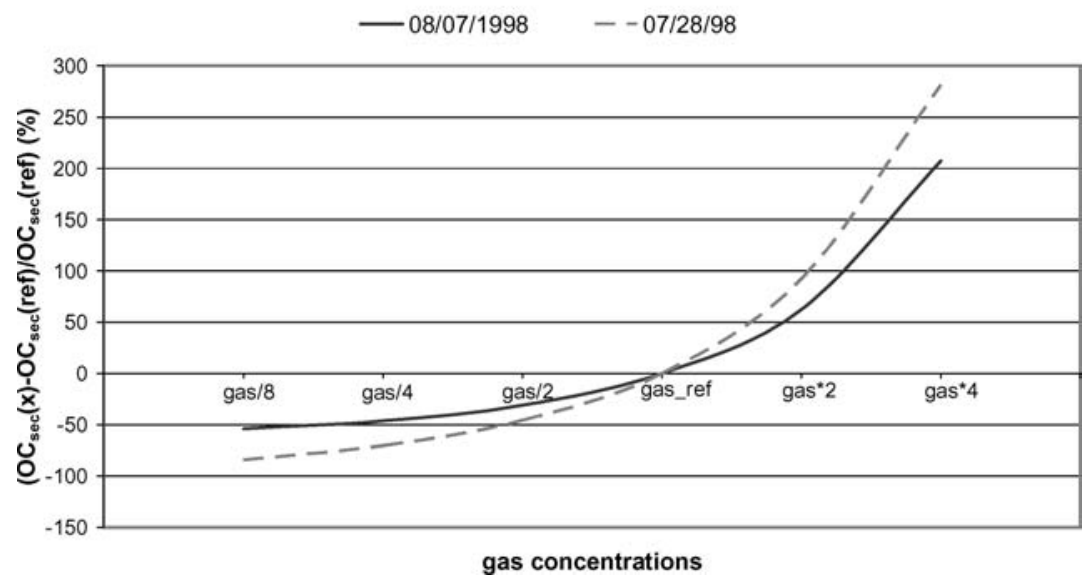

Figure 5. Relative increase of $\mathrm{OC}_{\mathrm{sec}}(\%)$. (a) For different particle emissions and (b) for different gas emissions.

multiplied by a factor of 8,4 or 2 . As expected, it is shown that the secondary aerosol formation is highly dependent on the initial concentrations of aerosols or precursor gases. Also, it may be seen that the response to gas changes is much more important than the one obtained through changes in aerosol concentration levels: the range varies from $-85 \%$ to almost $300 \%$ for gases whereas only from $-14 \%$ to $33 \%$ for particles. It is interesting to note that significant differences occur between the two meteorological situations illustrated in Figure 5a. On 07/28/98, increase or decrease in particle emissions have a weaker impact on SOA formation when compared to $08 / 07 / 98$. The impact of aerosol concentrations thus seems to be more important for the day with less favourable conditions (high temperature, low relative humidity) for SOA formation. Indeed the number of aerosols might play an 
Table II. Simulated $\mathrm{BC} / \mathrm{OC}_{\mathrm{tot}}$ ratios (\%) for two different initial background concentration conditions at 0:00

\begin{tabular}{llll}
\hline Initialisation type & Date $(9-21 \mathrm{~h})$ & $\begin{array}{l}\text { Mean simulated } \\
\mathrm{BC} / \mathrm{OC}_{\text {tot }} \text { ratio (\%) }\end{array}$ & $\begin{array}{l}\text { Mean measured } \\
{\mathrm{BC} / O C_{\text {tot }} \text { ratio (\%) }}\end{array}$ \\
\hline Init-mean & $01 / 25 / 00$ & 42 & No data \\
& $08 / 07 / 98$ & 37 & 32 \\
Init-norm & $07 / 28 / 98$ & 24 & 21 \\
& $01 / 25 / 00$ & 46 & No data \\
& $08 / 07 / 98$ & 23 & 32 \\
& $07 / 28 / 98$ & 20 & 21 \\
\hline
\end{tabular}

Note. "Init-mean" with the average daily concentrations obtained by a $24-\mathrm{h}$ spin-up the day before. "Init-norm" with concentrations obtained at 00:00 after a 24-h spin-up the day before.

important role to allow the transfer of the high gaseous organic precursors amount into particulate phase. The situation is different in Figure $5 \mathrm{~b}$ where conditions of SOA formation remain more favourable on 07/28/98 than on 08/07/98 (more hot, less humid), whatever the initialisation.

The initialisation procedure (called init-mean) relies on average background aerosol concentration values obtained by a $24 \mathrm{~h}$ spin-up performed for the previous day. Sensitivity tests were conducted by changing background concentrations of primary $\mathrm{BC}$ and $\mathrm{OC}$ particles by applying the init-norm test. Let us recall that the init-norm test refers to an initialisation with instantaneous concentrations taken at 24:00 LT at the end of the spin-up. Comparisons of $\mathrm{BC} / \mathrm{OC}_{\text {tot }}$ ratios obtained for the two different initialisations are shown in Table II. The initialisation procedure may be seen to have an important impact on $\mathrm{BC} / \mathrm{OC}_{\text {tot }}$ values.

For summer, $\mathrm{BC} \mathrm{OC}_{\text {tot }}$ ratios are much lower in the new (init-norm case) simulation than in the previous (init-mean case) one. This is mainly due to higher primary organic aerosol concentrations for the new case: $\mathrm{BC}$ concentrations are multiplied by 1.5 (for August 7th and July 28th), $\mathrm{OC}_{\mathrm{p}}$ by 2.1 and 2.5 (for August 7th and July 28th, respectively). In addition, differences in $\mathrm{OC}_{\mathrm{sec}}$ concentrations between the two cases are small as compared to differences in primary organic aerosol concentrations. Indeed, differences between secondary aerosol formation rates between init-norm and init-mean situations are slightly negative ( -15 and $-37 \%)$, which means that the secondary aerosol formation is favoured under the mean (not extreme) conditions. The difference between the two initialisation conditions is less pronounced for $07 / 28 / 98$ than for $08 / 07 / 98$. It seems that for this day $(07 / 28 / 98)$ with particularly optimal conditions for secondary organic carbon formation, the initialisation conditions are less influent.

For winter days, the variation in primary aerosol concentrations between the two initialisations is of the same order, 1.4 both for $\mathrm{BC}$ and $\mathrm{OC}_{\mathrm{p}}$. Same tendency is observed for the two other winter days. 
Finally, it was observed that comparisons of simulations with experimental data are worst for all days with the init-norm conditions.

\section{Conclusion}

Using the 0-D ORISAM aerosol module, tests were performed to simulate aerosol formation and ageing over Paris during the ESQUIF experiment for summer 1998 and winter 2000.

The module parameterizations allow to reproduce trends in the formation of secondary organic particles (SOA) and differences found experimentally between summer and winter aerosols. Moreover, in spite of the difficulty to accurately obtain actual BC and OC aerosol contents (still subject to debate), the few experimental black carbon to organic carbon ratio values available for this comparison are well reproduced for the summer season. No validation has been possible for winter due to lack of measurements, though there is still a general agreement for qualitative comparisons.

The module sensitivity to different changes was tested, such as temperature, relative humidity, initial size distribution, background particulate concentrations and emissions of gases and primary carbonaceous aerosol. The most important effect is certainly that of temperature. This temperature effect shows a marked threshold value $\left(20^{\circ} \mathrm{C}\right)$ at both seasons above which VOC transfer from the gas to particulate phase could be reduced, thus precluding any further important SOA formation. Further tests are ongoing to check if this threshold value is found at other sites. Changes in gas emissions have been shown to have a large impact on SOA formation too. Further investigations are needed to test the relative importance of chemically different VOC precursors. Unexpectedly, the aerosol size distribution has no quantifiable impact on the SOA formation, so further developments should be proposed for the parameterisation of $\mathrm{OC}_{\mathrm{sec}}$ formation to account for the role of particle surface areas, in particular effective thermodynamic links of inorganic and organic species and particles (Pun et al., 2002).

Changes in aerosol number appear of poor importance and a weak effect only of particulate background concentrations may be observed. It may be hypothesized that under unfavourable hot conditions when the gas to particle transfer is slowed down by high temperature, the need of aerosol sites active for absorption processes, could be then more determinant.

This preliminary work needs to be confirmed and completed by other studies over different areas in order to conclude if this type of module is able to reproduce SOA formation in a wide range of situations without considering more complex parameterisations. Tests on the impact of different combustion sources (biogenic/anthropogenic, fossil fuel/biomass burning) are ongoing. Furthermore, 1D and 3D aerosol modelling studies with ORISAM have allowed to test successfully along with the particulate phase transformations, the particle transport as well as wet and dry depositions (Cousin et al., 2005). 


\section{References}

Atkinson, R. W., Anderson, H. R., Sunyer, J., Ayres, J., Baccini, M., Vonk, J. M., Boumghar, A., Forastiere, F., Forsberg, B., Touloumi, G., Schwartz, J. and Katsouyanni, K., 2001: Acute effects of particulate air pollution on respiratory admissions: Results from the APHEA 2 project. Air pollution and health: A European approach, Am. J. Respir. Crit. Care Med. 164(10 Pt 1), 18601866.

Bessagnet, B., 2000: Modélisation de l'aérosol carboné - cas particulier des particules fractales de combustion. PhD Thesis. Université Paul Sabatier. Toulouse.

Bessagnet, B. and Rosset, R., 2001: Fractal modelling of carbonaceous aerosols-application to car exhaust plumes, Atmos. Environ. 35, 4751-4762.

Brauer, M., Hoek, G., van Vliet, P., Meliefste, K., Fischer, P., Gehring, U., Heinrich, J., Cyris, J., Bellander, T., Lewne, M., and Brunekreef, B., 2003: Estimating long-term average particulate air pollution concentrations: Application of traffic indicators and geographic information systems, Epidemiology 14(2), 228-239.

Cachier, H., Aulagnier, F., Sarda, R., Gautier, F., Masclet, P., Besombes, J.-L., Marchand, N., Despiau, S., Croci, D., Mallet, M., Laj, P., Marinoni, A., Deveau, P.-A., Roger, J.-C., Putaud, J.-P., Van Dingenen, R., Dell'Acqua, A., Viidanoja, J., Martins-Dos Santos, S., Liousse, C., Cousin, F., and Rosset, R., 2005: Aerosol studies during the ESCOMPTE experiment: An overview, Atmos. Res. 74, 547-563.

Castro, L. M., Pio, C. A., Harrison, R. M., and Smith, S. J. T., 1999: Carbonaceous aerosol in urban and rural european atmospheres. Estimation of the secondary organic carbon concentrations, Atmos. Environ. 31, 2771-2781.

Charlson, R. J., Schwartz, S. E., Hales, J. M., Cess, R. D., Coakley, J. A., Jr, Hansen, J. E., and Hofmann, D. J., 1992: Climate forcing by anthropogenic aerosols, Science 255, 423430.

Chazette, P. and Liousse, C., 2001: A case study of optical and chemical ground apportionment for urban aerosols in Thessaloniki, Atmos. Environ. 35, 2497-2506.

Chung, S. H. and Seinfeld, J. H., 2002: Global distribution and climate forcing of carbonaceous aerosols, J. Geophys. Res. 107(D19), 4407.

Cooke, W. F., Liousse, C., and Cachier, H., 1999: Construction of a $1^{\circ} \times 1^{\circ}$ fossil fuel emission data set for carbonaceous aerosol and implementation and radiative impact in the ECHAM4 model, $J$. Geophys. Res. 104(22), 137-162.

Cousin, F., Liousse, C., Cachier, H., Bessagnet, B., Guillaume, B., and Rosset, R., 2005: Aerosol modeling and validation during ESCOMPTE 2001, Atmos. Environ. 39, 1539-1550.

Fassi Fihri, A., Suhre, K., and Rosset, R., 1997: Internal and external mixing in atmospheric aerosolsby coagulation: Impact on the optical and hygroscopic properties of the sulphate-soot system, Atmos. Environ. 31, 1393-1402.

Haywood, J. M. and Shine, K. P., 1995: The effect of anthropogenic sulfate and soot aerosol on the clear sky planetary radiation budget, Geophys. Res. Lett. 22(5), 603-606.

Jacobson, M. Z., 2002: Control of fossil-fuel particulate black carbon and organic matter, possibly the most effective method of slowing global warming, J. Geophys. Res. 107, 4410.

Kanakidou, M. and Tsigaridis, K., 2000: Human activity enhances the formation of organic aerosols by biogenic hydrocarbon oxidation, J. Geophys. Res. 12, 9243-9254.

Léon, J. F., Chazette, P., Pelon, J., Dulac, F., and Randriamarisoa, H., in press: Aerosol direct radiative forcing impact over the INDOEX area based on active and passive remote sensing, J. Geophys. Res.

Liousse, C., Guillaume, B., Michel, C., Junker, C., Grégoire, J. M., and Cachier, H., 2004: Recent Developments for Carbonaceous Aerosol Inventories of the 1950-2100 Time Period, International Carbonaceous Aerosol Conference, Vienna. 
Liousse, C., Penner, J. E., Chuang, C., Walton, J. J., Edleman, H., and Cachier, H., 1996: A global three-dimensional model study of carbonaceous aerosols. J. Geophys. Res. 101, 1941119432.

Madronich, S. and Flocke, S., 1998: The role of solar radiation in atmospheric chemistry, in P. Boule (ed.), Handbook of Environmental Chemistry, Heidelberg, Springer-Verlag, pp. 1-26.

Mallet, M., 2003: Etude des propriétés microphysiques et optiques de l'aérosol en zone péri-urbaine durant Escompte. Estimation de l'impact radiatif direct. $\mathrm{PhD}$ thesis, University of Toulon and Var, $135 \mathrm{pp}$.

Nenes, A., Pilinis, C., and Pandis, S. N., 1998: ISORROPIA: A new thermodynamic model for inorganic multicomponent atmospheric aerosols, Aquat. Geochem. 4, 123-152.

Odum, J. R., Hoffmann, T., Bowman, F., Collins, D., Flagan, R. C., and Seinfeld, J. H., 1996: Gas/particle partitioning and secondary aerosol yield, Environ. Sci. Technol. 31, 1890-1897.

Penner, J. E., Chuang, C. C., and Liousse, C., 1996: The contribution of carbonaceous aerosols to climate change, in M. Kulmala and P. E. Wagner (eds.), Nucleation and Atmospheric Aerosols, Elsevier, New York, pp. 759-769.

Pun, B. K., Griffin, R. G., Seigneur, C., and Seinfeld, J. H., 2002: Secondary organic aerosol: 2. Thermodynamic model for gas/particle partitionning of molecular constituents, J. Geophys. Res. 107, 4333, doi:10.1029/2001JD000542.

Putaud, J.-P., Baltensperger, U., Bruggemann, E., Facchini, M. C., Fuzzi, S., Gehrig, R., Hansson, H. C., Harrison, R. M., Jones, A. M., Laj, P., Maenhaut, W., Mihalopoulos, N., Muller, K., Palmgren, F., Querol, X., Rodriguez, S., Spindler, G., ten Brink, H., Tunved, P., Van Dingenen, R., Wehner, B., Weingartner, E., Wiedensohler, A., Wahlin, P., and Raes, F., 2003: A European aerosol phenomenology. Physical and chemical characteristics of particulate matter at kerbside, urban, rural and background sites in Europe, Joint Research Centre, European Commission, EUR $20411 \mathrm{EN}$.

Ruellan, S. and Cachier, H., 2001: Characterisation of fresh particulate vehicular exhausts near a Paris high flow road, Atmos. Environ. 35, 453-468.

Schmidt, H., Laskus, L., Abraham, H. J., Baltensperger, U., Lavanchy, V., Bizjak, M., Burba, P., Cachier, H., Crow, D., Chow, J., Gnauk, T., Even, A., Brink, H. M. T., Giesen, K. P., Hitzenberger, R., Hueglin, C., Maenhaut, W., Pio, C., Carvalho, A., Putaud, J. P., Toom-Sauntry, D., and Puxbaum, H., 2001: Results of the "carbon conference" international aerosol carbon round robin test stage 1, Atmos. Environ. 25, 2111-2121.

Sheehan, P. E. and Bowman, F. M., 2001: Estimated effects of the temperature on secondary organic aerosol concentrations, Environ. Sci. Technol. 35(11), 2129-2135.

Solmon, F., 2001: Modélisation méso-échelle des émissions biogéniques d'hydrocarbures volatiles en France. Thesis. Institut Nationale d'Agronomique. Paris-Grignon.

Stockwell, W. R., Kirchner, F., Kuhn, M., and Seefeld, S., 1997: A new mechanism for regional atmospheric chemistry modeling, J. Geophys. Res. 102, 25847-25879.

Wang, S. C., Paulson, S. E., Grosjean, D., Flagan, R. C., and Seinfeld, J. H., 1992: Aerosol formation and growth in atmospheric organic/ $\mathrm{NO}_{x}$ systems - I. Outdoor smog chamber studies of $\mathrm{C}_{7}$ - and $\mathrm{C}_{8}$-hydrocarbons, Atmos. Environ. A 26, 403-420. 